\title{
Negotiating Values for the Science Curriculum: \\ The Need for Dialogue and Compromise
}

\author{
Susan J. Gribble, Léonie J. Rennie, Louise Tyson \\ Curtin University of Technology \\ Catherine Milne \\ University of Wollongong \\ Wendy Speering \\ St Hilda’s Anglican School For Girls
}

Acknowledgment:

An earlier version of this paper was presented at the Australasian Science

Education Research Association Conference, Darwin, Northern Territory, July, 1998. At the time this work was done, all of the authors were at Curtin University of Technology. 


\title{
Negotiating Values for the Science Curriculum: \\ The Need for Dialogue and Compromise
}

\begin{abstract}
Recently, a Curriculum Framework has been developed and mandated for implementation in all school systems - government, Catholic and independent - in Western Australia (WA). A statement of core shared values is a significant part of the Framework. The curriculum is divided into eight learning area statements, science being one of these. The Science Learning Area Statement, with its roots in the Australian Education Council (1994) statement on science, includes a definition of science and a rationale for teaching it in schools; major outcome statements concerned with working scientifically and developing conceptual understandings; principles for science learning, teaching and assessment; and sections about science as it relates to different phases of schooling, and how science can be integrated into other areas of the curriculum. Thirty two core shared values have been espoused as integral to the Curriculum Framework. These values have been clustered into five main statements: a pursuit of knowledge and a commitment to achievement of potential; self acceptance and respect for self; respect and concern for others and their rights; social and civic responsibility; and environmental responsibility. One of the main tasks for us as writers of the Science Learning Area Statement was to explicate the core shared values into a description of the science curriculum. This article documents, from our point of view, the process by which a mandated set of core shared values were incorporated into a statement describing the curriculum in the science learning area. The process was under the direction of a Science Learning Area Committee. At several points, conflict, or potential conflict, about the interpretation of the core shared values in relation to science in the classroom was resolved by negotiation amongst ourselves in the first instance, the Science Learning Area Committee, and the Values Consultative Group. While the central narrative in this paper is about our journey through the process, there are the antecedent themes relating to how and why the core shared values were developed and subsequently mandated. The arising tensions, as yet unexplored, relate to how, or even whether, the values might be explicated in science classrooms. In reflecting on these tensions, we provide a re-analysis of some of the issues in school science, which of course are not new. We believe that science as taught in classrooms cannot be value-free, even when teachers believe otherwise.
\end{abstract}




\section{What Is Meant by Values in Education?}

According to Hill (1991), values in education remains an elusive concept. Much of the slipperiness starts with terms such as values, beliefs, and attitudes. The definitions of these terms are much debated. Often a value is described as a person's belief about the nature of existence, reality, other human beings, and the world. It is especially to do with judgements of worth or, as we might say, a value judgement. The intensity of the values to which we attach high priority in the ways we think, relate, and act, reflect our attitudes. Our strong convictions and feelings dispose us to make choices according to our value system. Halstead (1996) defines values as "the principles, fundamental convictions, ideals, standards, or life stances which act as general guides or as points of reference in decision-making or the evaluation of beliefs or actions and which are closely connected to personal integrity and personal identity" (p. 5).

Hill (1991) believes that it is important for teachers to understand the difference between the cognitive, affective and volitional dimensions of a value statement. Teaching about a value does not mean that a student will be committed to the value. Also, "while it is legitimate to require students in a formal classroom situation to develop capacities of knowing and feeling, it is an invasion of their private space to demand conformity or agreement to [a value] as the price of a favourable formal assessment of their learning” (p. 5). Poole (1995), who raises several dilemmas about making values explicit in the science curriculum, affirms this idea. There is one view that values should not be examined in classrooms but merely be accepted as assumptions. Another view is that it is not the task of teachers to examine values because of the diversity of worldviews in a society, thus consensus of values is neither possible nor even desirable. A further view is based on the fear that a process of indoctrination develops because "there are complications arising from the powerful emotional and volitional factors alongside the cognitive ones" when values are explored in classrooms (Poole, 1995, p. 17).

From a philosophical perspective, debates exist about human rationality, pluralism, and relativism. Because "science itself has a metaphysical basis" and is dominated by the concepts of ontology, epistemology and axiology, these debates become complex (Poole, 1995, p. 18). In science what counts as truth or knowledge is central to these debates. However, if the political value of democracy is upheld, then a curriculum that endorses critical rationality and impartial analysis of curriculum 
content goes some of the way to ensure that students are not merely conditioned or indoctrinated (Hill, 1991). It is important that students learn to think seriously about their values, how they are formed, and their commitment to them. Students will need to consider what is important to them and how their values shape their behaviour towards others and their actions in everyday life.

Education in modern societies has to take the existence of a plurality of values into account, and so it cannot neglect that there will be conflict between values. Indeed, values will sometimes be the very factor which leads people into conflict. (Haydon, 1997, p. 42, emphasis in original)

While conflict between values may not necessarily be undesirable, in science the potential for disagreement about metaphysical matters is ever present. In school science, values will be contested, especially when working with controversial topics. In a multicultural society like Australia not everyone shares, or even understands, the same values. Schools serve communities with diverse value systems, communities that are at the same time connected to the wider society. A society, however, could not exist without some form of common values. Halstead (1996) argues that unless schools and educational systems "make the effort to articulate their values and develop some clarity of vision, they will not be in a strong position to pursue their task of developing pupils' understandings of values and helping pupils to develop their own commitments” (p. 8). A shared value system gives a sense of direction to schools within their communities.

The purpose of this paper, therefore, is twofold. First, we tell the story of our experiences in trying to state a mandated set of core shared values explicitly in a science curriculum statement. The decision-making process that identified and agreed on a set of core shared values for the curriculum framework was the responsibility of a specific and specialised group, the Values in Education Committee, and it was the Curriculum Council (1998) which “determined that core shared values should be explicitly articulated within the curriculum framework” (p. 324). As writers we began our work with an overview of the development of the core shared values and the processes used to have them argued. We set out our own value position as we entered the writing process, and document the processes of negotiation, dialogue and compromise which culminated in the final version of the Science Learning Area Statement. Second, we reflect on the tensions inherent in a mandated Science Learning Area Statement. We speculate on the implications and challenges for schools and teachers endeavouring to implement the new Curriculum Framework relating to science and the core shared values. 


\section{Background to the Process}

Development of the Core Shared Values

When the Curriculum Council (initially an Interim Council before endorsement by government legislation) was established in WA one of its tasks was to develop a Curriculum Framework which would be mandated for implementation in all school systems in WA. Within the Curriculum Council structure, an Overarching Committee steered the development of the Curriculum Framework and was supported in its work and progress by a raft of other committees. One of the committees, the Values in Education Committee, was responsible for identifying a "minimum set of core values ... considered generally to be held by members of Australia's multicultural society, taking into account certain shared values which are distinctive to Aboriginal culture” (Curriculum Council, 1998, p. 324). Generally, "the starting point in developing the values was the undertaking of an audit of existing value frameworks around Australia” (p. 324). "In particular, extensive use was made of the NPDP Values Review Project work from WA” (Curriculum Council, 1997, p. 322). The National Professional Development Program (NPDP) Values Review Project was commenced in 1993 as a Commonwealth government funded initiative in each State. In WA, this Project provided insight into how values could be explicitly integrated into curriculum development in two ways. First, the NPDP Values Review Project commenced by exploring the possibility of reaching consensus across the major education employer groups in the State about explicit value statements in curriculum development work. This process of negotiation and collaboration showed how an exemplary practice in curriculum development could be successful. Second, it was recognised in the NPDP Values Review Project that the core shared value statements needed to be relevant to a multicultural and pluralistic society. By 1994 an Agreed Minimum Values Framework document was produced representing statements about Ultimate, Democratic and Educational values that could be considered by all school sectors for incorporation into their curriculum statements (Caple, 1996). During 1995 and 1996 the Agreed Minimum Values Framework was field-tested across the school systems in the State to explore its applicability in schools.

Based on their own work and the NPDP project, the Values in Education Committee documented for the Curriculum Council thirty two core shared value 
statements (Curriculum Council, 1997, 1998). These value statements were clustered into five main categories as follows:

- a pursuit of knowledge and a commitment to achievement of potential;

- $\quad$ self acceptance and respect for self;

- respect and concern for others and their rights;

- $\quad$ social and civic responsibility; and

- environmental responsibility.

These core shared values were provided to each of the eight Learning Area Committees, such as the Science Learning Area Committee, formed by the Overarching Committee to develop learning area statements. The task of the Science Learning Area Committee and us as writers, therefore, was to acknowledge, promote and integrate these identified values in the Science Learning Area Statement.

\section{The Position of the Writers}

As the team of five writers who were contracted to write the Science Learning Area Statement, our challenge was to work at the direction of the Science Learning Area Committee, yet bring our collective experience and knowledge to the writing task. It was essential to concentrate on producing a statement that met the design brief which was to combine the core shared values into statements about: a definition of science and a rationale for teaching it in schools; outcome statements concerned with working scientifically and developing conceptual understandings; and principles for the learning, teaching and assessment of science in classrooms. Also, we needed to describe how science related to different phases of schooling and how science can be integrated into other areas of the curriculum. At the same time, as writers, we believed that there should be an emphasis on developing scientific literacy for students from kindergarten to Year 12. We considered it important to imbue the Statement with a message that science is a social activity and students should be able to use their knowledge and understanding about science in personal decision-making and in everyday life (Rennie, 1998). Learning science provides people with the capacity to create visions for a preferred future and to create possibilities for a future that can be celebrated.

Also, the writing team believed it was important to highlight in a curriculum statement what counts as scientific knowledge, that science is culturally contextualised because people's world views affect how they interpret science in their 
day to day lives, and that science is not a value-free endeavour. Of significance was

infusing the idea that science teachers needed to involve their students in

being initiated into the ideas and practices of the scientific community and making these ideas and practices meaningful at an individual level. The role of the science educator is to mediate scientific knowledge for learners to help them to make personal sense of the ways in which knowledge claims are generated and validated, rather than to organise individual sense-making about the natural world. (Driver, Asko, Leach, Mortimer, \& Scott, 1994, p. 6)

As writers, therefore, we believed that school science should empower the individual for personal and collective action because the processes and knowledge that students learn in science should have relevance to them and enable them to live and work for the common good that connects everyone. Students need to critically analyse what is valued in science, who values it, and where is it valued.

\section{The Task: Developing the Science Learning Area Statement}

\section{The Role of the Science Learning Area Committee}

The major task of the Science Learning Area Committee was to direct us as the contracted writers to compose, on behalf of the Committee, the Learning Area Statement. The design brief for the initial development and writing of the Statement clearly set the expectation that the core shared values would be embedded into the Statement. Throughout the drafting of the Science Statement, the public consultation period for the Curriculum Framework, and the revision of the Science Statement, the writers were ultimately at the direction of the Committee. As writers, however, we always believed our intellectual freedom was not constrained. From the outset the relationship we had with the Committee was harmonious. This positive relationship remained mutually beneficial during the whole period of our contract. It was because of this relationship that often we were asked for our opinions, advice, and suggestions for direction rather than merely being the "pens" for the Committee. Additionally, a reference group of science experts in the community was convened to advise the Science Learning Area Committee. This group provided valuable feedback about the draft Statement and generally supported the document. The significant reason that the Science Learning Area Committee was successful in its work was because the Committee was steered by strong but democratic leadership. The chairperson, Dr. Pam Garnett, was an insightful thinker and a highly respected science educator in WA, and was able to facilitate and negotiate consensus decision-making, especially 
when debates were polarised or times were testing under the direction of the Overarching Committee which was responsible for the Curriculum Framework as a whole.

\section{Drafting the Science Statement}

Over a period of eight months, we attended many regular meetings with the Science Area Learning Committee and an inclusivity workshop to grapple with the substance of the Science Learning Area Statement. Before we met with it, the Committee had determined from the 32 core shared value statements those that should be priorities for explicit reference in the Science Learning Area Statement. In response to the question, "What values would you expect to see in Science?”, the Committee had arrived at the priorities through a voting process. Summing the votes derived the priority of the values. The value statement with the most votes became the priority core shared value statement to be included in science. The core values seen by the Committee as essential in the Statement for science were: an open learning environment, empowerment, pursuit of knowledge, the benefits of research, conservation of the environment, sustainable development, diversity of species, and rehabilitation. (It must be noted that rehabilitation did not remain as a separate value statement but was later incorporated into the sustainable development value.) In the first meeting between the Committee and us, the Committee conceded that not all of the thirty two values would be relevant to science and we were instructed to emphasise those that were voted the highest priority.

Decisions about how these values were phrased and where they were placed in the Statement were left with us. It was interesting to note, however, that as the drafting process of the Statement progressed, differences in Committee members' views about science and several of the value statements, both prioritised and nonprioritised statements in the prior voting process, gradually emerged. Each draft tabled for discussions at meetings challenged Committee members' own beliefs about school science. The debates especially focused on how the discipline of science should be represented in school science. Some members saw the discipline of science as universal, in the way that Stanley and Brickhouse (1994) describe. A universal science is characterised by a number of fundamental beliefs. First, there is a direct correspondence between reality and our observations of that reality. Second, there exist universal truths or scientific facts that can be uncovered by the application of one true scientific method. Finally, scientific knowledge is value-free and the beliefs 
and values of scientists, and of the culture to which they belong, have no influence on the type of research that is conducted or the knowledge that is produced. As Cross (1995) points out, this view in a science curriculum "includes the mythology that science is an unproblematic value free body of knowledge which is independent of human beings” (p. 158). There were several Committee members who seemed to hold these beliefs.

Other Committee members thought that the Statement should acknowledge the contribution of people from a broad range of cultural backgrounds to the development of science and the dynamic interaction between science and culture. Acceptance of multiple perspectives presents a richer, more interesting, and more representative picture of science and it also acknowledges that science develops from multiple ways of knowing. This means that scientific knowledge is derived from many perspectives, but as Longino (1988) argues, "scientific knowledge - although not the product of some uniquely truth producing method - is nevertheless a specific form of knowledge” (p. 574). However, this does not mean that every view of science (or explanation of phenomena) has equal value. As Gough (1994) warns, "we need to distinguish more carefully between the naive appropriation of another culture's belief systems and the understandings that may be generated by comparative readings of their mythologies and ours” (p. 194).

\section{The Re-Emerging Position of the Writers}

While these debates remained unresolved, consensus usually emerged about how we would develop ideas in the draft writing. Our values position prevailed when developing drafts for review. Discussion and negotiation at a Committee meeting directed any change to the text. We based our writing drafts on three premises: the pursuit of knowledge; science as a cultural construction; and the centrality of students to the learning process. These premises provided us with the flexibility to weave most of the thirty two values into the Statement. The following illustrations serve to portray how our stance was used to draft the Science Statement which was approved by the Committee.

First, we believed that the conceptual areas in the Statement foster the quest for knowledge as each student strives to understand the natural world and how best to make a contribution to this world. Ideas concerned with developing students' understandings about "the interdependence of all living things" and "how changing one aspect of the environment will affect other organisms” were stated (Curriculum 
Council, 1997, p. 219). Also, ideas about students' thinking and action were captured in statements like "students should critically analyse the impact on their local environment of human activity" (p. 211) and that "an appreciation of scientific knowledge, processes and values has the potential to enable students to build a more productive and ecologically sustainable world” (p. 216). For example, the breadth and depth of knowledge that students should develop were described in terms of how students' understandings about industrial processes should enable them to "critically investigate the developments designed to make such processes more efficient and ecologically sensitive” (p. 218), why students should understand "that energy has renewable and non-renewable sources", and the types of "social issues involved in energy production” (p. 220). Several statements were included about the benefits of science. The mention of ideas encompassed in statements like "the applications of science transform large parts of human existence in social, political and economic contexts" illustrates the need for students to know about the ways science impacts on human activity (p. 211).

Second, science as a cultural construction was emphasised by us in the Statement in several ways. For example, science was described as a "human activity which uses distinctive ways of valuing, thinking and working to understand the natural world" (Curriculum Council, 1997, pp. 210) and students should "have a sense of history of science, its relationship with other human endeavours and how it contributes to society” (p. 215). The exploration of different value systems and the right to develop their own value systems were made explicit in the Learning Statement as these two examples illustrate: "students contrast the ideas and beliefs held by people of different cultures" (p. 211); and "understanding science helps people to develop a personal perspective of their role in the world” (p. 217). Issues of inclusivity were addressed and it was stated clearly that diverse world views could be acknowledged and respected in science education. Also included was the notion that, while it is understood that some explanations about the natural world may not be acceptable to the scientific community, different explanations need to be acknowledged in science education alongside more scientifically acceptable ideas. Different explanations can be culturally or spiritually bound or be indicative of learners' everyday ideas because they have not been exposed to alternative conceptions.

Third, we addressed the centrality of students in the learning process through an approach of empowering students in an open learning environment. Statements 
were composed to resonate with the belief that science has the potential to enable students to be questioning, reflective and critical thinkers by providing them with particular ways of looking at the world and by emphasising the importance of evidence to construct conclusions. Also, empowered individuals can "initiate and manage change” (Curriculum Council, 1997, p. 211). Student empowerment could be acquired through science education by accessing the knowledge in the conceptual strands, developing reflective and critical analysis skills, initiative, responsibility, and the language of science. Importantly, a clause in the Statement was that students needed to apply this knowledge and these skills when using the powerful inquiry process associated with working scientifically. In the Science Statement there was strong emphasis on individual learning styles, learning and assessment which are contextually relevant, quality interactions in the learning process and "extending students' confidence in their own abilities and encouraging excellence” (p. 233). Fundamentally, the Committee and we held firmly to the idea that learning can only be done by the learner and it is the responsibility of teachers to plan and implement a science program which promotes opportunities for all students to learn. The teacher's task, therefore, is to challenge and extend learners' ideas. An openness to new learning is facilitated when teachers create a learning environment which is supportive in allowing students to take risks within the learning process, locating information and communicating their findings and understandings to others, and where they can generate knowledge through questioning, collecting evidence, analysing, and testing ideas. In the end, students should have the capacity to synthesise scientific concepts with a range of other information to solve practical problems in their everyday life.

Through the sustained period of meetings, writing, and responding to critical reading of drafts, the Committee negotiated a final version of the Draft Science Statement with us. This Statement was included in the Curriculum Framework which was printed and distributed widely across the school sectors and the community for public comment. Prior to the final completion of the Draft Statement, we were requested by the Overarching Committee (through the Science Learning Area Committee) to audit the Statement in terms of how the thirty two values were explicitly or implicitly stated in the document. The values audit undertaken by us satisfied the Committee that most of the values had been addressed in the Statement. Later, differences of opinion became evident on this matter. 


\section{The Consultation Period}

For a period of seven months the draft Curriculum Framework was scrutinised by many different groups; teachers, parents, administrators in education, religious groups, and politicians. “The Values Consultative Group, was formed to provide expertise and direction in refining the final set of core shared values" (Curriculum Council, 1998, p. 324). One specific task conducted by the Values Consultative Group was an audit of each of the learning area statements. Groups of specialists, specialists in science for example, were brought together to ascertain how the core shared values had been described in the learning area statements and to ascertain how the core shared values had been implicitly or explicitly expressed into the learning area statement. At the end of the consultation period, a consultant researcher analysed the responses gathered during the consultation process and provided a report to the Curriculum Council.

Science did not fair too well in the values audit. What seemed obvious to us as writers and the Committee was not obvious to a range of readers. This response was similar to the other learning areas. There were two main issues concerned with reference to all of the 32 value statements in the Science Learning Area Statement. First, it was debated whether all of the values were relevant to a science statement. The expectation following the values audit was that all the 32 value statements applied to the Science Learning Area Statement. Some values, however, were not easily transferable into the Statement. While reference from a scientific perspective could be made to "recognising and observing human rights" it was more difficult to be explicit about "respect for legitimate and just authority structures and the rules of law.” The authority and rules of law in science carry a different philosophical meaning. A similar dilemma existed with making a statement about how science contributed to "recognising a secure, caring and supportive family environment."

Second, and a more keenly debated issue, was whether values should be explicit or implicit in the Statement. Explicit reference, as defined by the Values Consultative Group after the audit of the Statement, appeared to mean that the value needed to be stated exactly as it was written in the Values Framework. As writers, we had consciously embedded most of the core shared values articulated by the Curriculum Council into the Learning Area Statement because they fitted with the ideas that were being expressed in relation to science. For example, the value of ethical behaviour and responsibility was implied in working scientifically and in the conceptual areas such as the Life and Living strand when referring to topics such as: 
"humans controlling reproduction, altering genes and changing lifestyles of other organisms” (Curriculum Council, 1997, p. 220). In many instances, however, the wording of the values did not match exactly the text of the Values Framework.

As writers, we wondered whether the people, as readers, who conducted the values audit might not have recognised a value statement expressed from a science view unless it matched the text in the Values Framework. The task for us in this case was merely to adjust text. An interesting part of this process was that even though many of the values associated with environmental responsibility cluster were not written explicitly (that is, value statements in the Science Statement did not match word for word those in the Values Framework), the auditors did not have the same difficulty in identifying these values in the Science Statement because words such as 'environment', 'sustainability', 'diversity', and 'conservation' appeared to carry some meaning for the auditors. It was obvious that these types of values were directly related to the science area.

Members of the writing team were invited to a workshop on values. The purpose of the workshop was to support writers from all the learning areas in developing a clearer understanding of how best to embed the core shared values into the learning area statements. From this workshop it became evident to us that even within the Values Consultative Group there was a difference of opinion about what was meant by making values explicit. Were values explicit only when worded precisely as in the Values Framework? Often this exact wording did not sit well within the science context. Would it be sufficient if the values were expressed using different wording more suited to the discipline and genre of science? The decisions made remained with the Science Learning Area Committee.

\section{Drafting the Revision of the Statement}

For another three month period, we met with a smaller, reconstituted Science Learning Area Revision Group (with the same chairperson) to negotiate the revision of the Statement and respond to any significant messages that were evident from the consultation process. By this time there had been a slight revision of the Values Framework and the dilemma of wording the values in the Science Statement was considered. The decision was made to make the most suitable and acceptable compromise where possible in the revised Statement. One major task for us was to follow the direction given by the Values Consultative Group. As many as possible of the 32 core shared values needed to be transparent in the Science Statement. The core 
shared values that were directly related to science needed to be explicit in the rationale of the Statement. We were able to accommodate this request to the satisfaction of the Group, and at the same time, ensure that more of the text in the Science Statement, in respect to values, matched that of the Values Framework.

The 18-month journey to write the Science Learning Area Statement has ended for us. Nevertheless, we continue to ponder the future of school science in WA schools and classrooms and the depth of impact the Curriculum Framework will have on students' learning. We know that the literature on 'top-down' curriculum change contains a litany of reasons for the failure of this type of curriculum implementation. While we are unsure about the success of the implementation of the Science Learning Area Statement, we believe that it has the potential to create change. However, we acknowledge that curriculum initiatives do not necessarily lead to institutionalisation of the innovation in the day-to-day practices of teachers. Much must transpire for this to happen. From our experience as a group of writers, we are convinced that many teachers will need to re-analyse their views about science, the way students learn, and the way they are taught and assessed. These issues, of course, are not new. What is new is the articulation of a set of core shared values in science teaching and learning, an aspect of education that has been ignored for many years.

\section{Core Shared Values: What Might They Mean for Teachers?}

The Values Framework articulated in the Curriculum Framework defines a set of core shared values to be advocated through the teaching and learning of school science. As writers, we had no direct influence on the construction of the Values Framework. During the writing process our influence on how the core shared values were embedded into the Science Learning Area was more substantial. The task of writing the values into the Science Learning Area Statement was relatively straightforward, however, in comparison to the task of espousing these values within the complexity of schools and classrooms which are socially and culturally situated. As alluded to in this paper, we attempted to embed values into the Science Statement at the developmental stage by working and collaborating with a range of people who held different beliefs on several issues, including the core shared values. The values of negotiation, compromise and tolerance were well learned by us. Open dialogue for consensus was imperative. Implementing school science under the Curriculum Framework, therefore, has the potential for conflict for teachers and students. In 
reflection, we believe the conflict for teachers will reside in two main issues. The move to outcomes-based approaches to education requires educators to consider first, how values are shaped and dealt with in the curriculum, and, second, how curriculum content and pedagogy will change.

Outcomes-Based Education and Core Shared Values: What is Mandated and What is Assessed?

In many developed countries there has been mandated curriculum reform. Mandated government initiated 'top-down' reform, based on hegemonic knowledge developed outside of the school and classroom, historically has not been successful. The Curriculum Framework has been developed, albeit through collaboration and consultation with over 10,000 people, including teachers and community members outside of schools. From a critical perspective, it still needs to be recognised that the valued knowledge to be learned by students has been defined by so-called curriculum experts. Given this analysis, however, the Curriculum Framework follows a worldwide trend towards outcomes-based education. There is wide ranging use of this term but Willis and Johnston (1998) describe the conception exemplified in the Curriculum Framework.

Rather than focussing on what should be in the curriculum taught to students, outcomes-based approaches focus on what students are expected to be like as a result of those experiences. These descriptions of expected outcomes are intended to form the basis of curriculum planning and evaluation. That is, outcomes both precede, and provide a framework for, decisions about curriculum content and approach and also provide the basis for the monitoring of the 'success' of schools or the system as a whole. (p. 123)

The outcomes in the Curriculum Framework are explicit descriptions for schools about "what is expected for students to know, understand, be able to do, or to be like as a result of their school education" (Willis \& Johnston, 1998, p. 123). The ideal in an outcomes-based approach to curriculum is that students should be able to transform their knowledge and skills into successes after they leave school (Spady, 1993; Spady \& Marshall, 1991). Thus, defining outcomes of significance in a curriculum statement is crucial (Spady, 1994). Can we assume that the outcomes in the Science Learning Area Statement are those that students in the next millennium need to know and be able to do in science?

Critics of outcomes-based education view the approach as curriculum manipulation (Smythe \& Dow, 1997). Smythe (1993) maintains that schools need to be places where there is "less measurement against standards of performance, and 
more concern with the ways of enabling teachers to connect with the lives of their students” (p.18). The technical rationality of assessing students according to outcome descriptions, a predictable, standardised way of monitoring teaching and learning, overshadows the micro-realities of schools and classrooms which are stamped by doubt, uncertainty and unpredictability. Schools and classrooms are places where teachers and students mediate meaning of their different social and cultural worlds.

Science teachers will be expected to measure student achievement according to the outcome statements. At the same time, we believe that science teachers are not expected to measure the core shared values as outcomes. The core shared values underpin the Curriculum Framework in principle. "Systems, sectors and schools may add to this minimum set or interpret and promote the values in relation to their particular ethos or mission statement” (Curriculum Council, 1998, p. 8). It must be noted that this type of statement is not made in connection with the outcomes. Student achievement will be judged according to the scientific processes and concepts, the outcomes, they have learned but not the core shared values. For example, students will be assessed on how they act responsibly using "ethical considerations of the processes and likely products of science on people and the environment”, and not on what their value judgements and beliefs happen to be or the position or stance they may take in a debate (Curriculum Council, 1998, p. 220). The core shared values are the spirit and essence that support students' thinking to develop their ethical and moral considerations by studying science at school.

In the current politicised educational climate of the times, science teachers in WA will need to balance these tensions. Working scientifically and scientific understandings, expressed as outcomes, are mandated and will guide teachers' future curriculum planning, teaching and assessment. Part of the reconciliation for teachers will concern whether these are the only outcomes that students will need to learn in science. Is there other valued knowledge that has not been expressed in the outcomes? Will teachers be able to add other outcomes to their own school-based curriculum development? Also, teachers will need to foster the core shared values as part of their mandate. The subtlety of assessing an outcome but not a shared core value may be lost in the day-to-day realities of classrooms. More to the point, teachers may remain oblivious to the meanings of outcomes and core shared values because the 'top-down' implementation process may follow its previous fateful history. 


\section{Content and Pedagogy: What will Change?}

The central tenet of an outcomes-based curriculum is that there can be common outcomes but they can be achieved through uncommon curricula (Willis \& Johnston, 1998). Different students vary in their learning styles, rates, motivations and interests.

The content and teaching in classrooms need to allow for:

differing starting points and pathways to learning so that students are not left out, or left behind; allow for different strategies and approaches that meet varying learning styles and needs; allow for the reality that different areas of study are differentially relevant (and will be differently pursued) in various communities because of geographic, economic, topological, and cultural consideration; and allow for the prospect that students' demonstrations of their knowledge will be grounded in these contextual differences. (Darling-Hammond, 1994, p. 489)

These ideas may be liberating for teachers if they accept the premise of an outcomes approach to teaching. As long as they assess the outcomes defined in the Curriculum Framework, they retain the professional responsibility for the content and practice of their teaching. We anticipate, however, that teachers will face great challenges when advocating the core shared values through the content of science and the approaches they use in their teaching repertoire.

The challenges for teachers in selecting the content of the school science curriculum are two-layered. One challenge will arise because of the differing views about the nature of science. Some science teachers may think that the content of science can be taught in a value-free way. However, particular values about science are clearly implicit in many of the resources, such as texts and popular literature, used in the classroom. As Milne (1996, 1997, 1998) argues, all science taught in school science can be thought of as stories in which meaning and values are embedded. In her research she found that many teachers believe that only facts and theories are taught in school science and teachers use stories to make science more interesting for students. However, she claims that these science stories are so familiar that the valuemessages they convey have become invisible. She asserts that accounts of scientific discoveries, for example, the relationship between the pancreas and the control of blood sugar, often portray the justification of scientific discoveries as the 'real' science rather than the discoveries themselves. This embedded value has implications, not only for the way that teachers represent discovery in science but also for the way that teachers apply this model of discovery in their conception of teaching and learning. Another value-message is that scientific knowledge is "discovered” in Nature rather than considering, as another possibility, that science can be thought of 
as being constructed by humans. From this perspective, science knowledge, therefore, is tentative. Teachers will need to consider the implications of their selection of science content in terms of the meanings and values they transmit in the accounts that they present to learners.

A second challenge in school science content will arise when dealing with controversial topics such as genetic engineering, abortion, the environment, the treatment of animals, or taking action to support particular causes. With these types of topics, not only will scientific values be in conflict but also personal, religious and cultural values about such topics will be confronted. The core shared values in the Curriculum Framework attempt to provide a common ground for the discussion and critical analysis of these issues. The Curriculum Framework makes a set of core shared values transparent for teachers. The classroom climate that is conducive to open, respectful discussion about controversy, however, will be in the hands of the teacher.

Increasingly, teachers will need to be aware that values are embedded not only in the content of their science curriculum but in the way they teach. Recognising the core shared values in the Science Learning Area Statement at the text level, especially those implied rather than stated explicitly, is a starting point. Reconciling these with their own beliefs is another part of teachers’ planning for school science. Every teacher has an individual set of values that shapes teaching and interactions with students, although Haydon (1997) suggests that the difficulty at the classroom level is not so much about teachers accepting a defined set of values "but in recognising precisely what this endorsement will mean in practice” (p. 11). Even when teachers accept the view that science is a value-laden construction from multiple perspectives and inquiry methods, challenges in working with the Curriculum Framework will become evident. Change will be necessary in their teaching and assessment practices. How will they open up the classroom and create a learning environment where critical and analytical thinking in science are promoted and values can be explored? How will teachers build an atmosphere in science learning situations that supports students expressing their ideas and presenting their points of view without fear of being incorrect or inaccurate? What will teachers' tolerance levels be when students' ideas may not always be scientifically acceptable and preferred answers may not always be given in response to questions? What will assessment procedures look like in this more open approach? Will these assessment procedures actually measure the outcomes, that is, what students have learned? 
As a team of writers we remained committed to our beliefs and values about science in schools. Throughout their science learning, we believe students should develop skills and attitudes that allow them to be open to wide ranging ideas in their quest for new knowledge and to be disposed to making intellectually honest and discerning judgements. Science learning adds to students' ability to use initiative and enterprise coupled with responsible actions in meeting the challenges of everyday life and work. They learn how and why a commitment to a set of values is part of being human and how a freely chosen way of living should be in accord with the natural environment and with those around them. This is our value stance. In the main, a similar position is reflected in the Curriculum Framework. Why should teachers work towards these sorts of scientific ideals?

\section{Concluding Note}

As writers, the task of preparing the Science Learning Area Statement based on a set of shared core values was a rewarding and exciting challenge for us. The Science Learning Area Revision Group was comfortable with the final version of the Science Statement, although many compromises were reached through open dialogue, as they should have been, by the time the final version was produced. In this paper we have tried to show that a set of core shared values, decided upon by others, creates conflict for people when placed in a curriculum document, especially when the curriculum is mandated. At the same time, we have tried to explain that the exposition of these values through the teaching and learning of science provides the potential for students to become critical thinkers about ethical dilemmas in order to make their own sense of the natural world around them. We do not see that these values should be measured in any way but how students' values are influenced and developed through studying school science is important for teachers to understand. The manner in which the intended Science Learning Area Statement is enacted in classrooms, of course, remains to be seen. The need for research about the shaping of values through science education is evident and presents a challenge for researchers in the field. 


\section{References}

Australian Education Council. (1994). A statement on science for Australian schools. Carlton, Victoria: Curriculum Corporation.

Caple, K. (1996, September). Values in education: National Professional Development Program (NPDP). Paper presented at the Australian Council for Education Administration and the Australian College of Education National Conference, Perth.

Cross, R. (1995). Conceptions of scientific literacy. Research in Science Education, 25(2), 150-162.

Curriculum Council. (1997). Curriculum framework: Consultation Draft. Perth, Western Australia: Author.

Curriculum Council. (1998). Curriculum framework. Perth, Western Australia: Author. URL http://www.curriculum.wa.edu.au/pages/framework/framework00.htm Darling-Hammond, L. (1994). National standards and assessment: Will they improve education? American Journal of Education, 102, 478-510.

Driver, R., Asko, H., Leach, J., Mortimer, E., \& Scott, P. (1994). Constructing scientific knowledge in the classroom. Educational Researcher, 23(7), 5-12.

Gough, N. (1994). Playing at catastrophe: Ecopolitical education after post structuralism. Educational Theory, 44(2), 189-210.

Halstead, M. (1996). Values and values education in schools. In J. M. Halstead, \& M. J. Taylor (Eds.), Values in education and education in values (pp. 3-14). London: The Falmer Press.

Haydon, H. (1997). Teaching about values: A new approach. London: Cassell.

Hill, B. (1991). Values education in Australian schools. Melbourne: Australian Council for Educational Research.

Longino, H. (1988). Science, objectivity and feminist values. Feminist Studies, 14, 561-574.

Milne, C. (1996). Is it fair science? School science stories of discovery. In E. Godfrey (Ed.), Proceedings of the Second Australasia and South Pacific Region GASAT Conference (pp. 86-95). Auckland, New Zealand: University of Auckland.

Milne, C. (1997). The representation of "acid” in school chemistry: From concept to fact. Chemeda: The Australian Journal of Chemical Education, 46, 8-18. 
Milne, C. (1998). Philosophically correct science stories? Examining the implications of heroic science stories for school science. Journal of Research in Science Teaching, 35, 175-187.

Poole M. (1995). Beliefs and values in science education. London: Open University Press.

Rennie, L. J. (1998). Capacity building in science: Support the vision, renounce the tabula rasa. Studies in Science Education, 31, 71-136.

Smythe, J. (1993). Education and economic rationalism: Have we lost our way? Adelaide, South Australia: The Flinders University of South Australia.

Smyth, J. \& Dow, A. (1997). What's wrong with outcomes? Spotter planes, action plans, and targeted groups at the margins of the educational landscape. Occasional paper No 11. Adelaide, South Australia: The Flinders University of South Australia. Spady, W. (1993). Outcomes-based education. Belconnen, Australian Capital Territory: Australian Curriculum Studies Association.

Spady, W. G. (1994). Choosing outcomes of significance. Educational Leadership, 51(6), 18-22.

Spady, W. G., \& Marshall, K. J. (1991). 'Beyond traditional outcome-based education’. Educational Leadership, 49(2), 67-72.

Stanley, W. B., \& Brickhouse, N. W. (1994). Multiculturalism, universalism and science education. Science Education, 74, 387-397.

Willis, S., \& Johnston, J. (1998). Is it possible to base systemic curriculum reform on principles of social justice? In C. Keitel (Ed.), Social justice and mathematics education. Gender, class, ethnicity, and the politics of schooling (pp. 123-134). Berlin, Germany: Freie Universität Berlin. 